\title{
A clinical study of patients with central venous catheter associated bloodstream infections in a tertiary care hospital
}

\author{
R. Abisha Rezia ${ }^{1}$, R. Vijendra ${ }^{1 *}$, Anjana Gopi² \\ ${ }^{1}$ Department of Pharmacology, Kempegowda Institute of Medical Sciences, Bangalore, Karnataka, India \\ ${ }^{2}$ Department of Microbiology, Kempegowda Institute of Medical Sciences, Bangalore, Karnataka, India
}

Received: 29 July 2020

Accepted: 01 September 2020

\author{
*Correspondence: \\ Dr. R. Vijendra, \\ Email: vijendra_ramaiah@yahoo.co.in
}

Copyright: () the author(s), publisher and licensee Medip Academy. This is an open-access article distributed under the terms of the Creative Commons Attribution Non-Commercial License, which permits unrestricted non-commercial use, distribution, and reproduction in any medium, provided the original work is properly cited.

\begin{abstract}
Background: Central venous access puts the patients at risk of iatrogenic complications and is associated with bloodstream infections. Staphylococcus aureus, Staphylococcus epidermidis, Staphylococcus saprophyticus and Methicillin Resistant Staphylococcus aureus (MRSA) are responsible for at least two-thirds of the infections followed by Klebsiella pneumoniae, Escherichia coli, Pseudomonas aeruginosa, Enterococcus spp and Acinetobacter spp. Due to the scarcity of Central Venous Catheter associated Blood Stream Infections (CVC-BSI) data, this study was taken up in our tertiary care hospital.

Aims: This study is aimed to study the profile of organisms causing CVC-BSI, assess their antimicrobial susceptibility, the clinical course and outcome.

Methods: All subjects whose central venous catheter samples $(n=84)$ were sent for culture and sensitivity during the study period were included in this prospective observational study. The study was done in the Department of Microbiology from July 2019 to December 2019. The catheter tips were streaked onto blood agar plate using Roll plate technique. After biochemical identification of the organisms, antimicrobial susceptibility testing was performed by modified Kirby-Bauer disc diffusion method as per the Clinical Laboratory Standard Institute (CLSI) guidelines.

Results: Growth of pathogens was seen in $64.3 \%(\mathrm{n}=54)$. The common organisms were Coagulase Negative Staphylococcus aureus (CONS) in $27.78 \%(\mathrm{n}=15)$, Enterococcus spp, Klebsiella pneumoniae in $14.8 \%$ each $(\mathrm{n}=8)$ and Acinetobacter spp in $11.1 \%(\mathrm{n}=6)$. Resistance was seen with amoxicillin + clavulanic acid, cefepime, ciprofloxacin and cefoperazone. The organisms were sensitive to levofloxacin, tetracycline and vancomycin.

Conclusion: Aseptic precautions taken by the healthcare personnel will bring down the infections and curb the spread of multi-drug resistant hospital acquired infections.
\end{abstract}

Keywords: Central venous catheter, Bacteriological profile, Antimicrobial drug resistance

\section{INTRODUCTION}

Central Line Associated Blood Stream Infections (CLABSI) is defined as clinical signs of infection, such as culture growth of the same bacteria from blood taken from a central line catheter or catheter tip and peripheral vein in a patient who did not have a source of infection other than the catheter. ${ }^{1}$ CLABSI is also defined as development of blood stream infection within 48 hours of insertion of central line with laboratory-confirmed blood stream infections (BSI) (not related to an infection at another site). ${ }^{2}$ BSIs due to central venous catheterization are one of the major device-associated infections in the intensive care unit (ICU). It can be a source of sepsis, bacteraemia, multi organ failure and even death. ${ }^{3}$ Central venous catheters are used for delivery of medication and parenteral nutrition, hemodynamic monitoring and for collection of blood samples. ${ }^{4}$ CLABSI results from bacterial colonisation of the catheters and may lead to 
significant clinical problem. ${ }^{5}$ It increases hospital cost and length of stay. The incidence of CLABSI varies between ICUs due to differences in type of catheters used, insertion and utilization techniques and frequency of catheter manipulations. ${ }^{6}$ Coagulase-negative Staphylococci (CoNS), and Staphylococcus aureus are the common causes of catheter related blood stream infections. ${ }^{7,8}$ Acinetobacter baumannii has recently emerged as a leading cause of nosocomial bloodstream infections in the intensive care unit (ICU) and associated with high mortality. ${ }^{9,10}$ Knowledge about the prevalence of catheter related infections and the profile of the organisms would help in infection control. The objective of this study was to study the profile of pathogens causing Central Venous Catheter associated Blood Stream Infections (CVC-BSI) in a tertiary care hospital in South India and also assess their antimicrobial susceptibility pattern, clinical course and outcome.

\section{METHODS}

This study was a prospective, observational clinical study conducted in the Department of Microbiology at Kempegowda Institute of Medical Sciences and Research Centre, Bangalore. The study was conducted between July 2019 and December 2019 after approval by the Institutional Ethics Committee (IEC). The study was registered with Clinical trial registry- India (CTRI). All the subjects $(n=84)$ whose central venous catheter samples were sent for culture sensitivity during the abovementioned study period were the participants for this study (Non-probability sampling: convenience sampling). Central venous catheter samples of 84 study subjects were examined for eligibility. Samples of 54 subjects were confirmed to be eligible, included in the study, completed follow-up and analysed. Data regarding the age, gender, reason for hospitalization, use of empirical antimicrobials, source of the central venous catheter samples, the organisms cultured, and their sensitivity and resistance patterns were noted. The subjects were followed up during their course in the hospital.

Inclusion criteria included subjects with Central venous catheters (CVCs) in situ for $>3$ days of insertion and sterile blood culture immediately after catheterization and subjects whose CVC tip samples when processed showed significant growth of one or more organisms.

Subjects who got CVC inserted outside our hospital were excluded from the study.

CVC tips collected from the patients were streaked onto blood agar plate using the Roll plate technique. Growth of $>25$ colonies was considered as significant growth. If needed, sub-cultures were done. Gram positive and gram negative organisms were identified. After biochemical identification of the organisms, antimicrobial susceptibility testing was performed on Muller Hinton agar plates by modified Kirby-Bauer disc diffusion method as per the Clinical Laboratory Standard Institute (CLSI) guidelines.

The data collected were analysed and the results were depicted in the form of percentages, graphs or bar charts.

\section{RESULTS}

A total of 84 central venous catheter samples that were sent for culture sensitivity during the study period were analysed.

The length of stay in the hospital ranged from 3 days to 15 days.

Table 1: Demographic profile.

\begin{tabular}{|lll|}
\hline Variables & $\mathbf{N}(\%)$ \\
& $\begin{array}{l}\text { Infants } \\
\text { (1 month to 1 year) }\end{array}$ & $1(1)$ \\
\cline { 2 - 3 } $\begin{array}{l}\text { Age } \\
\text { (years)*\# }\end{array}$ & $\begin{array}{l}\text { Adolescents } \\
\text { (11 to 19 years) }\end{array}$ & $\begin{array}{l}\text { Adults } \\
\text { (up to 60 years) }\end{array}$ \\
\cline { 2 - 3 } & $\begin{array}{l}\text { Elderly } \\
\text { (> 60 years) }\end{array}$ & $56(67)$ \\
\hline Gender & Male & $26(31)$ \\
\cline { 2 - 3 } & Female & $56(67)$ \\
\hline
\end{tabular}

*Age of the subjects ranged from 4 months to 85 years \# Mean age $596 \pm 213.5$ months

Table 2: Case distribution.

\begin{tabular}{|c|c|c|}
\hline & & $\mathbf{N}(\%)$ \\
\hline \multirow{2}{*}{$\begin{array}{l}\text { Distribution } \\
\text { of the cases }\end{array}$} & Culture positive & $54(64.3)$ \\
\hline & No growth & $30(35.7)$ \\
\hline \multirow{6}{*}{$\begin{array}{l}\text { Source of } \\
\text { the cases }\end{array}$} & $\begin{array}{l}\text { Emergency medicine } \\
\text { ICU }\end{array}$ & $33(39)$ \\
\hline & Orthopedics ICU & $21(25)$ \\
\hline & General surgery ICU & $14(17)$ \\
\hline & General Medicine ICU & $13(15)$ \\
\hline & $\begin{array}{l}\text { Respiratory medicine } \\
\text { ICU }\end{array}$ & $2(2.4)$ \\
\hline & Peadiatrics ICU & $1(1.2)$ \\
\hline \multirow{2}{*}{$\begin{array}{l}\text { Source of } \\
\text { the } \\
\text { specimen }\end{array}$} & $\begin{array}{l}\text { Site of the central } \\
\text { venous catheter }\end{array}$ & $\begin{array}{l}\text { Internal } \\
\text { Jugular Vein }\end{array}$ \\
\hline & $\begin{array}{l}\text { Single / multiple lumen } \\
\text { catheter }\end{array}$ & $\begin{array}{l}\text { Single } \\
\text { lumen } \\
\text { catheter }\end{array}$ \\
\hline \multirow{8}{*}{$\begin{array}{l}\text { Catheter in- } \\
\text { situ (no. of } \\
\text { days) }\end{array}$} & 2 & $11(13.1)$ \\
\hline & 3 & $17(20.24)$ \\
\hline & 4 & $12(14.29)$ \\
\hline & 5 & $12(14.29)$ \\
\hline & 6 & $14(16.67)$ \\
\hline & 7 & $9(10.71)$ \\
\hline & 8 & $8(9.52)$ \\
\hline & 9 & $1(1.19)$ \\
\hline
\end{tabular}


The reasons for hospitalization in the emergency medicine ICU was Organophosphorus poisoning $(n=5)$, Chronic kidney disease (CKD) $(n=6)$, fulminant hepatic failure $(n=1)$, left lower lobe pneumonia $(n=4)$, sepsis $(n=4)$, congestive cardiac failure $(n=5)$, cerebrovascular accident $(n=2)$, road traffic accident with head injury $(n=3)$ and ischemic heart disease $(n=3)$. The patients were admitted to the orthopaedics ICU $(n=21)$ following post traumatic fractures.

Hospitalization to the general surgery ICU was for acute pancreatitis $(n=5)$, explorative laparotomy $(n=4)$, necrotising fascitis $(\mathrm{n}=2)$ and gangrenous appendicitis $(n=3)$. Admission to the general medicine ICU was due to CKD $(n=9)$ and sepsis $(n=4)$.

Table 3: Profile of culture positive pathogens causing central venous catheter associated blood stream infection.

\begin{tabular}{|ll|}
\hline Culture positive organisms $(\mathbf{n = 5 4})$ & $\mathbf{N}(\%)$ \\
\hline Coagulase-negative staphylococci & $15(27.78)$ \\
\hline Klebsiella spp* & $10(18.5)$ \\
\hline Enterococcus spp\# & $8(14.8)$ \\
\hline Acinetobacter spp\# & $6(11.1)$ \\
\hline Psedumonas aeruginosa & $4(7.4)$ \\
\hline Escherichia coli & $3(5.56)$ \\
\hline Enterobacter spp\# & $2(3.7)$ \\
\hline Methicillin resistant Staphylococcus aureus & $2(3.7)$ \\
\hline Candida tropicalis & $2(3.7)$ \\
\hline Staphylococcus aureus & $1(1.9)$ \\
\hline Non fermenting gram negative bacilli & $1(1.9)$ \\
\hline
\end{tabular}

*Klebsiella pneumoniae: $\mathrm{n}=8$, Klebsiella oxytoca: $\mathrm{n}=2$; \#Speciation was not conducted.

Table 4: Culture positive pathogens and resistance pattern.

\begin{tabular}{|c|c|}
\hline Organisms & Resistance shown to antimicrobial agents \\
\hline \multirow{3}{*}{ Coagulase-negative staphylococci $(\mathrm{CoNS})(\mathrm{n}=15)$} & $\beta$-lactam antibiotics* $(n=9)$ \\
\hline & Macrolides\# $(n=3)$ \\
\hline & Fluoroquinolones $\dagger(n=3)$ \\
\hline \multirow{4}{*}{ Klebsiella spp $(\mathrm{n}=10)$} & $\beta$-lactam antibiotics* $(n=3)$ \\
\hline & Fluoroquinolones $\dagger(n=2)$ \\
\hline & Aminoglycoside $+(n=3)$ \\
\hline & Carbapenams $\S(n=2)$ \\
\hline \multirow{3}{*}{ Enterococcus $\operatorname{spp}(\mathrm{n}=8)$} & $\beta$-lactam antibiotics $*(n=3)$ \\
\hline & Aminoglycoside $\ddagger(n=3)$ \\
\hline & Macrolides\# $(n=2)$ \\
\hline \multirow[b]{2}{*}{ Acinetobacter $\operatorname{spp}(\mathrm{n}=6)$} & $\beta$-lactam antibiotics* $(n=3)$ \\
\hline & Aminoglycoside $+(n=3)$ \\
\hline \multirow{2}{*}{ Psedumonas aeruginosa $(n=4)$} & $\beta$-lactam antibiotics* $(n=2)$ \\
\hline & Aminoglycoside $+(n=2)$ \\
\hline \multirow{2}{*}{ Escherichia coli $(\mathrm{n}=3)$} & $\beta$-lactam antibiotics* $(n=2)$ \\
\hline & Fluoroquinolones $\dagger(\mathrm{n}=1)$ \\
\hline Enterobacter $\operatorname{spp}(\mathrm{n}=2)$ & $\beta$-lactam antibiotics* $(n=2)$ \\
\hline Methicillin resistant Staphylococcus aureus $($ MRSA) $(n=2)$ & $\beta$-lactam antibiotics* and methicillin $(\mathrm{n}=2)$ \\
\hline Staphylococcus aureus $(\mathrm{n}=1)$ & $\beta$-lactam antibiotics* $(\mathrm{n}=1)$ \\
\hline Non fermenting Gram negative bacilli $(\mathrm{NFGNB})(\mathrm{n}=1)$ & $\beta$-lactam antibiotics* $(n=1)$ \\
\hline
\end{tabular}

Table 5: Culture positive isolates and sensitivity pattern.

\section{Organisms}

Coagulase-negative staphylococci $(\mathrm{CoNS})(\mathrm{n}=15)$

Klebsiella spp $(\mathrm{n}=10)$

\section{Sensitive AMAs}

Vancomycin $(\mathrm{n}=8)$

Clindamycin $(n=4)$

Gentamicin $(n=3)$

Clindamycin $(\mathrm{n}=6)$

Vancomycin $(n=4)$ 


\begin{tabular}{|c|c|}
\hline Organisms & Sensitive AMAs \\
\hline \multirow{2}{*}{ Enterococcus spp $(\mathrm{n}=8)$} & Vancomycin $(n=3)$ \\
\hline & Levofloxacin $(n=5)$ \\
\hline \multirow{2}{*}{ Acinetobacter spp $(n=6)$} & Meropenem $(n=4)$ \\
\hline & Ciprofloxacin $(n=2)$ \\
\hline \multirow{2}{*}{ Psedumonas aeruginosa $(n=4)$} & Levofloxacin $(n=2)$ \\
\hline & Meropenem $(n=2)$ \\
\hline \multirow{2}{*}{ Escherichia coli $(\mathrm{n}=3)$} & Meropenem $(n=1)$ \\
\hline & Gentamicin $(n=2)$ \\
\hline Enterobacter spp $(\mathrm{n}=2)$ & Imipenam, Meropenem $(n=2)$ \\
\hline Methicillin resistant Staphylococcus aureus (MRSA) $(n=2)$ & Meropenem $(n=2)$ \\
\hline Staphylococcus aureus $(\mathrm{n}=1)$ & Gentamicin, levofloxacin $(n=1)$ \\
\hline Non fermenting Gram negative bacilli (NFGNB) $(\mathrm{n}=1)$ & Meropenem $(n=1)$ \\
\hline
\end{tabular}

Table 6: Use of empirical antimicrobials.

\begin{tabular}{|c|c|c|}
\hline Organism & Empirical antimicrobials $(n=64)$ & Indication for use of the AMA \\
\hline \multirow{5}{*}{ Acinetobacter spp $(\mathrm{n}=5)$} & Faropenam $(n=1)$ & Chronic Kidney Disease \\
\hline & Gentamicin $(n=1)$ & CKD with suspected UTI \\
\hline & Meropenam $(n=1)$ & Dengue fever \\
\hline & Imipenam $(n=1)$ & Bicondylar fracture shaft of right tibia \\
\hline & Cefoperazone + sulbactam $*(n=1)$ & $\begin{array}{l}\text { Cerebrovascular accident with right } \\
\text { hemiplegia }\end{array}$ \\
\hline \multirow{2}{*}{ Candida tropicalis $(\mathrm{n}=2)$} & Clindamycin $(\mathrm{n}=1)$ & Necrotising fascitis of left thigh \\
\hline & Meropenam $(n=1)$ & CKD with urosepsis \\
\hline \multirow{5}{*}{$\begin{array}{l}\text { Coagulase-negative } \\
\text { staphylococci }(\mathrm{CoNS})(\mathrm{n}=18)\end{array}$} & Meropenam $(n=8)$ & $\begin{array}{l}\text { Pneumonia }(n=1) \text {, acute pancreatitis }(n=1) \text {, } \\
\text { CKD }(n=6)\end{array}$ \\
\hline & Piperacillin + tazobactam* $(n=3)$ & $\begin{array}{l}\text { Fulminant hepatic failure }(n=1) \text {, } \\
\text { Organophosphorous poisoning }(n=1) \text {, Acute } \\
\text { kidney injury }(n=1)\end{array}$ \\
\hline & Ceftriaxone $(n=2)$ & Chronic kidney disease $(n=2)$ \\
\hline & Cefoperazone + sulbactam $*(n=4)$ & Acute kidney injury $(n=4)$ \\
\hline & Linezolid $(\mathrm{n}=1)$ & Chronic kidney disease $(n=1)$ \\
\hline \multirow{3}{*}{ Escherichia coli $(\mathrm{n}=3)$} & Piperacillin + tazobactam* $(n=1)$ & OP poisoning $(\mathrm{n}=1)$ \\
\hline & Metronidazole $(\mathrm{n}=1)$ & Gangrenous appendicitis $(n=1)$ \\
\hline & Cefoperazone + sulbactam* $(n=1)$ & Post traumatic fracture of right femur $(n=1)$ \\
\hline Enterobacter spp $(\mathrm{n}=1)$ & Cefotaxime $(n=1)$ & RTA with head injury $(n=1)$ \\
\hline \multirow{3}{*}{ Enterococcus $\operatorname{spp}(\mathrm{n}=9)$} & Meropenam $(n=6)$ & Sepsis $(n=5)$, diffuse cerebral contusion $(n=1)$ \\
\hline & Piperacillin + tazobactam* $(n=2)$ & RTA with head injury $(n=2)$ \\
\hline & Linezolid $(\mathrm{n}=1)$ & Snakebite $(\mathrm{n}=1)$ \\
\hline \multirow{5}{*}{ Klebsiella spp $(\mathrm{n}=12)$} & Piperacillin + tazobactam* $(n=3)$ & $\begin{array}{l}\text { RTA }(n=1) \text {, acute subarachnoid haemorrhage } \\
(n=1) \text {, post explorative laparotomy }(n=1)\end{array}$ \\
\hline & Meropenam $(n=6)$ & Sepsis with CKD $(n=5)$, encephalitis $(n=1)$ \\
\hline & Cefpodoxime $(n=1)$ & Acute intestinal obstruction $(n=1)$ \\
\hline & Linezolid $(\mathrm{n}=1)$ & Acute intestinal obstruction $(n=1)$ \\
\hline & Polymixin $(n=1)$ & Diabetic foot with ulcer $(n=1)$ \\
\hline \multirow{2}{*}{$\begin{array}{l}\text { Pseudomonas aeruginosa } \\
(\mathrm{n}=8)\end{array}$} & Piperacillin + tazobactam* $(n=7)$ & $\begin{array}{l}\text { Cortical venous thrombosis }(n=1), \text { CKD with } \\
\text { suspected UTI }(n=6)\end{array}$ \\
\hline & Ceftriaxone $(n=1)$ & Post traumatic fracture of right clavicle $(n=1)$ \\
\hline \multirow{2}{*}{ Staphylococcus aureus $(\mathrm{n}=6)$} & Piperacillin + tazobactam* $(n=3)$ & Sepsis $(n=3)$ \\
\hline & Meropenam $(n=3)$ & Acute respiratory distress syndrome $(n=3)$ \\
\hline
\end{tabular}

*Fixed Dose Combinations (FDCs).

\section{DISCUSSION}

Central line associated bloodstream infection is a serious and one of the most common causes of hospital acquired infections worldwide. Central line associated blood stream infection may result from health care interventions and constitutes an important cause of morbidity and mortality among ICU patients. Formation of bacterial colonization in the catheter may be due to poor hygiene, occlusive 
dressing, moisture around the site of exit, nasal colonization and poor hand hygiene.

This study was aimed at finding out the profile of organisms causing contamination of the CVCs in hospitalized patients and also their antimicrobial resistance and sensitivity patterns.

In this study, 84 patients who had CVCs were studied. Clinical findings have shown that the prolonged usage of medical devices like venous catheters increase the risk of infection in the hospitalized patients in the ICU. Also, duration of hospitalization and duration of catheterization are two major determinants contributing to the incidence of these infections. ${ }^{11}$

According to the study results from the CVC samples, $64.3 \%$ cases $(n=54)$ had at least one kind of bacteria or fungus that grew in the culture media. Sharif et al in a study at the medical university of Kashan-Iran, showed that out of the 100 samples that were cultured, $29 \%$ cases had at least one kind of microorganism that grew in the culture media, which is less than the prevalence of infection in this study. In this study, the most common organism grown was Coagulase negative staphylococcus (CONS) which is similar to Sharif's study. ${ }^{12}$

Similar results were also shown by a study done in Gonder, Ethiopia, $24.2 \%$ by Ali and Kebede et al in 2008. ${ }^{13}$ Studies from India by Arora et al 2007 (20.02\%) and Sharma et al $2002(33.9 \%)$ also showed comparable results. ${ }^{14,15}$ Slight variation may be due to many factors like geographical locations, patient type, timing and number of blood cultures or difference in blood culture system. ${ }^{13-15}$

In a study done in Brazil by Grothe et al out of the 156 inpatients, 94 catheter samples were culture positive $(60 \%)$. Also in this study, patients whose catheters were put in the jugular vein, suffered from the CVC infection more than the patients who had their catheters put into the subclavian vein. ${ }^{16}$ In our study, the catheter was inserted in the internal jugular vein in all the patients, and only single lumen catheters were used.

Higher level of contamination is related to longer duration of hospitalization. Thus, care of the catheter, in the patients who are hospitalized in the ICU, is important. All these factors can reduce the incidence of CVC related infection.

Coagulase negative staphylococci $(43 \%, \mathrm{n}=6)$ was the commonest organism isolated in a study by Arti Ninama et al. Second most common organism was Klebsiella pneumoniae $(29 \%, \mathrm{n}=4)$ followed by Pseudomonas aeruginosa $(21 \%, \mathrm{n}=3)$ and Candida albicans $(7 \%, \mathrm{n}=1) .{ }^{17}$ These findings are similar to our study. Colonization of the catheter tip by staphylococcal infection is due to migration of skin organisms at the insertion site and gram-negative aerobes is because of infusate contamination and handling by health care personnel.
CoNS and Enterococcus spp isolates showed higher level of resistance to beta-lactam antibiotics than Staphylococcus aureus. However, all the three were sensitive to vancomycin which is similar to other studies. ${ }^{18,19}$ Most of the gram-negative bacteria were resistant to beta-lactam antibiotics. Among gram-negative bacterial isolates, Acinetobacter spp and Klebsiella spp were dominant species. This is similar to a study done by Manmeet Kaur Gill et al. ${ }^{20}$

Presence of diabetes was found to be a significant comorbid condition in our study which was same as the study by Jia et al. ${ }^{21}$ CoNS was a major isolate from the patients in our study. Similarly, Rodrigo et al observed that most common isolate as CoNS accounting for 54\%. ${ }^{22}$ CoNS was sensitive to vancomycin, teicoplanin and linezolid.

The resistance and sensitivity patterns of gram-negative isolates were similar to a study by Mansur et al. ${ }^{23}$

According to study by McGee and Gould, large percentage of CLABSIs can be minimized by proper application and use of full barrier precautions, aseptic skin preparation, the avoidance of femoral catheters, appropriate hand hygiene, use of antiseptic or antibiotic impregnated catheters, the removal of unnecessary catheters as early as possible and comprehensive educational programs for staff. ${ }^{24}$

\section{CONCLUSION}

The long duration of catheterization and colonization play an important role in development of the central line blood stream infection along with various other factors which causes septicemia and multi organ failure. Prolonged hospital stay of patients with catheterization leads to overburdening of the cost of treatment which can be minimized by using catheter lock solutions and application of local antibiotics. Even the deaths and co-morbid conditions can be reduced by regular surveillance of appropriate infection control practices. Culture results and sensitivity will also help to treat specific organism.

The antimicrobial sensitivity patterns of the common isolates provide guidelines for the physician in critical care medicine to start appropriate empirical antibiotic therapy depending upon the clinical scenario. This can be costeffective and can also prevent indiscriminate use of antibiotics.

\section{ACKNOWLEDGEMENTS}

Thankful to the Department of Microbiology for providing the necessary data.

Funding: No funding sources

Conflict of interest: None declared

Ethical approval: The study was approved by the Institutional Ethics Committee 


\section{REFERENCES}

1. Horan TC, Andrus M, Dudeck MA. CDC/NHSN surveillance definition of health care-associated infection and criteria for specific types of infections in the acute care setting. Am J Infect Control. 2008;36:309-332.

2. Yazan Haddadin; Hariharan Regunath. Central Line Associated Blood Stream Infections (CLABSI). Statpearls; 2017. Last accessed on 29 June 2020.

3. Gahlot R, Nigam C, Kumar V, Gupta M. Catheter related bloodstream infections in ICU: a study from North India. Int J Infect Control. 2013; v9i2:1-3.

4. Chopdekar K, Chande C, Chavan S. Central venous catheter-related blood stream infection rate in critical care units in a tertiary care, teaching hospital in Mumbai. Indian J Med Microbiology. 2011;29:169171.

5. Pal N, Sujatha R. Extreme drug resistant A.baumannii associated with CLA-BSI in Kanpur. Int J Res Med Sci. 2017;5:3620-5.

6. Abirami E. A study on Catheter related bloodstream infections (CRBSI) in Intensive care unit patients in a tertiary care hospital. Indian J Microbiol Res. 2017;4(2):138-143.

7. Raad I, Costerton W, Sabharwal U, Sacilowski M, Anaissie E, Bodey GP. Ultrastructural analysis of indwelling vascular catheters: a quantitative relationship between luminal colonization and duration of placement. The Journal of infectious diseases. 1993;168(2):400-7.

8. Cobb DK, High KP, Sawyer RG, Sable CA, Adams $\mathrm{RB}$, Lindley DA, et al. A controlled trial of scheduled replacement of central venous and pulmonary-artery catheters. The New England journal of medicine. 1992;327(15):1062-8.

9. Apostolopoulou E. Surviellance of Device associated infection rate and Mortality in 3 greek Intensive care units. Am J crit care. 2013;22(3); e12-e20.

10. Asmita A. Mehta V, Kumar A, Indira K, Suresh G. Nair, Dinesh KR, Singh SK. Risk factors for mortality in Acinetobacter calcoaceticus-baumannii Bacteraemia. Asian Pacific Journal of Tropical Biomedicine. 2012:S1852-S7.

11. Barsanti MC, Woetje KF. Infection prevention in the intensive care unit. Infect DisClin $\mathrm{N}$ Am. 2009;23:703-25.

12. Sharif A, Emami A, Mazouchi T, Mosavi S, Sharif M, Verdi J, et al. Venous catheter infection of patients admitted to ICU and its related factors. KAUMS Journal (FEYZ). 2002;6:53-8.

13. Ali J, Kebede Y: Frequency of isolation and antimicrobial susceptibility pattern of bacterial isolation from blood culture in Gondar University Hospital. Ethio Med J. 2008:46(2):155-161.
14. Arora U, Devi P. Bacterial profile of blood stream infections and antibiotic resistance pattern of isolates. J K Sci. 2007;9:186-190.

15. Sharma M, Goel N, Chaudhary U, Aggarwal R, Arora DR. Bacteraemia in children. Indian $\mathbf{J}$ Pediatr. 2002;69:1029-32.

16. Grothe C, da Silva Belasco AG, de CássiaBittencourt AR, Vianna LA, de Castro CintraSesso R, Barbosa DA. Incidence of bloodstream infectionamong patients on hemodialysis by central venous catheter. Rev Latino-am Enfermagem. 2010;18:73-80.

17. Ninama A, Golia S, Bohra S, Central line blood stream infection in intensive care unit: Importance of the care bundle, Int J Med Microbiol Trop Dis. 2019;5(1):1-3

18. Wasihun, A.G., Wlekidan, L.N., Gebremariam, S.A. Bacteriological Profile and Antimicrobial Susceptibility Patterns of Blood Culture Isolates among Febrile Patients in Mekelle Hospital, Northern Ethiopia. Springer Plus. 2015;4:314-16.

19. Soriano A, Marco F, Martinez JA, Pisos E, Almela M, Dimova VP. Influence of vancomycin minimum inhibitory concentration on the treatment of methicillin-resistant S. aureus bacteremia. Clin Infect Dis. 2008;46:193-200.

20. Gill MK, Sharma S. Bacteriological profile and antibiotic resistance pattern in blood stream infection in critical care units of a tertiary care hospital in North India. Indian J Microbiol Res. 2016;3(3):270-274.

21. Jia L, Yu H, Lu J, Zhang Y, Cai Y, Liu Y. Epidemiological characteristics and risk factors for patients with catheter-related bloodstream infections in intensive care unit. Zhonghua yi xue za zhi. 2015;95(9):654-8.

22. Deliberato RO, Marra AR, Correa TD, Martino MD, Correa L, Dos Santos OF, et al. Catheter related bloodstream infection (CR-BSI) in ICU patients: making the decision to remove or not to remove the central venous catheter. PLoS One. 2012;7(3):e32687.

23. Mansur FJ, Barai L, Karim MM, Haq JA, Fatema K, Faruq MO. Intravascular catheter related infections and antimicrobial susceptibility pattern of isolated bacteria in a tertiary care hospital of Bangladesh. Indian J Med Microbiol. 2014;32:68-71.

24. McGee DC, Gould MK. Preventing complications of central venous catheterization. N Engl J Med.2003; 348:1123-1133.

Cite this article as: Rezia RA, Vijendra R, Gopi A. A clinical study of patients with central venous catheter associated bloodstream infections in a tertiary care hospitalInt J Basic Clin Pharmacol 2020;9:1665-70. 